\title{
QUANDO APARECE A PRIMEIRA ESCAMA? ESTUDO COMPARATIVO SOBRE O SURGIMENTO DE ESCAMAS DE ABSORÇÃO EM TRÊS ESPÉCIES DE BROMÉLIAS TERRESTRES DE RESTINGA ${ }^{1}$
}

\author{
André Mantovani ${ }^{2}$ \& Ricardo Rios Iglesias ${ }^{3}$
}

\begin{abstract}
Resumo
(Quando aparece a primeira escama? Estudo comparativo sobre o surgimento de escamas de absorção em três espécies de bromélias terrestres de restinga) $\mathrm{O}$ aparecimento de tricomas foliares de absorção (escamas) é analisado em propágulos oriundos de reprodução sexuada (sementes) e assexuada (rametes) de três espécies de bromélias terrestres ocorrentes na restinga aberta de Barra de Maricá, Rio de Janeiro (22 $2^{\circ} 58^{\prime} \mathrm{S}-42^{\circ} 53 \mathrm{~W}$ ): Aechmea nudicaulis (L.) Griseb.; Neoregelia cruenta (Graham) L. B. Sm. e Vriesea neoglutinosa Mez. Nas três espécies, a germinação (emissão da radícula) ocorreu após três dias de tratamento. Os eventos "emissão da plúmula" e "completa expansão da plúmula com emissão da segunda folha" ocorreram respectivamente até 11 e 15 dias após a emissão da radícula em A. nudicaulis e N. cruenta. A análise morfológica em microscopia ótica e eletrônica não detectou escamas até 17 dias após a emissão da radícula. Entretanto pêlos radiculares ocorreram logo nos três primeiros dias de germinação em A. nudicaulis e N. cruenta. Para V. neoglutinosa, a análise morfológica detectou escamas na plúmula ainda em expansão, porém as escamas estavam em fase inicial de formação. Não foram detectados pêlos radiculares em plântulas de V. neoglutinosa durante o experimento. Escamas com desenvolvimento estrutural completo foram observadas nos primórdios foliares junto ao meristema apical do caule dos rametes das trêsespécies analisadas. Propõe-se aqui que o aparecimento de escamas nas primeiras folhas dos rametes confere alta capacidade de estabelecimento por via vegetativa para as bromélias estudadas na restinga de Barra de Maricá. Tal fato auxiliaria as espécies estudadas a superar a fase de estabelecimento de plântulas, intensamente limitada pelas condições abióticas vigentes nas restingas. Palavras-chave: Bromeliaceae, restingas, plântula, estabelecimento, rametes, tricomas.
\end{abstract}

\begin{abstract}
(When does the first absorptive trichome appear? Comparative analysis of the occurrence of absorptive trichomes in three terrestrial species of bromeliads from Brazilian sandy coastal plains (restinga)) The occurrence of absorptive leaf trichomes is studied in propagules originated from sexual (seeds) and assexual (ramets) reproduction from three terrestrial bromeliads in restinga of Barra de Maricá, Rio de Janeiro, Brazil

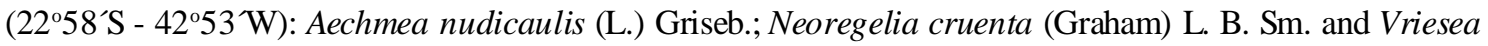
neoglutinosa Mez. For A. nudicaulis and $N$. cruenta, the radicle protrusion (germination) occurs in the third day of experiment. The complete expansion of the plumule and emission of the second leaf occur until 15 days after germination. For both species, no absorptive leaf trichomes were detected until day 17 of germination, but several root hairs appear in three days of germination. Results are different for V. neoglutinosa. Although radicle protrusion (germination) occurs in three days, the events "plumule emission" and "expanded plumule with second leaf emission" occurred after 15 and 18 days respectively. For this species, absorptive trichomes were detected yet in the young plumule, but still in the initial phase of differentiation. No root hairs occurred for $V$. neoglutinosa until the end of the experiment. Absorptive trichomes occurred in the shoot apical meristem from ramets of the studied species. Considering that the seedling phase is very sensible to harsh environments, we suggest that the occurrence of absorptive trichomes in the very first leaves of ramets, but not on young seedlings, represents an important adaptive capacity for the establishment of terrestrial bromeliads by assexual reproduction under the abiotic conditions of restinga.
\end{abstract}

Key-words: Bromeliaceae, sandy coastal plains (restingas), seedling, establishment, ramets, trichomes.

Artigo recebido em 08/2004. Aceito para publicação em 07/2005.

${ }^{1}$ Parte da Tese de Doutorado do primeiro autor

${ }^{2}$ Instituto de Pesquisa Jardim Botânico do Rio de Janeiro, Rua Pacheco Leão 915, Jardim Botânico, Rio de Janeiro, Brasil, CEP 22460-030. Programa Zona Costeira. email: andre@jbrj.gov.br

${ }^{3}$ Autor para correspondência: R. R. Iglesias - Universidade Federal do Rio de Janeiro, Cidade Universitária, Centro de Ciências da Saúde, Bloco A, Instituto de Biologia, Departamento de Ecologia, sala A2 102, Laboratório de Ecologia de Comunidades, Ilha do Fundão, Rio de Janeiro, RJ. Brasil, Caixa Postal 68020, CEP 21944.590, email: rir@biologia.ufrj.br 


\section{INTRODUÇÃ̃o}

A família Bromeliaceae apresenta diversos caracteres vegetativos que conferem aos seus integrantes alta capacidade de estabelecimento e sobrevivência sob condições adversas para a vida vegetal (Benzing 1990). Entre tais caracteres relevam-se o metabolismo CAM, a xeromorfia foliar, a suculência e a capacidade de acumular água e detritos entre as folhas do tanque (Benzing 2000). Entretanto, o caráter de maior relevância é a presença de tricomas foliares capazes de absorver água e nutrientes (Benzing 1976), ocorrentes principalmente nas subfamílias Bromelioideae e Tillandsioideae (Tomlinson 1969; Benzing 2000).

Os tricomas auxiliam na sobrevivência sob substratos secos e/ou oligotróficos, seja em ambientes epifíticos, epilíticos ou mesmo terrestres. Solos secos e oligotróficos são comumente encontrados nas áreas entre moitas de restinga aberta (Mantovani \& Iglesias 2002). Hay \& Lacerda (1980) e Hay et al. (1981) lançaram então a hipótese de que as bromélias poderiam sobreviver nestas áreas e agir como espécies potencialmente pioneiras. De fato, analisando nas áreas entre moitas o solo sob a bromélia Neoregelia cruenta com o solo sem vegetação, os autores observaram que sob a bromélia o solo era dotado de maiores porcentagens de matéria orgânica e capacidade de troca catiônica. Isto confere ao solo maior poder de retenção, e às plantas, maior disponibilidade de nutrientes. Em outras palavras, o estabelecimento, crescimento e posterior morte das bromélias forneceria material orgânico, produzindo um solo mais ameno para a colonização por outras plantas. Assim as bromélias desempenhariam um papel pioneiro e também facilitador na colonização das restingas, iniciando moitas em áreas abertas sem vegetação (Hay \& Lacerda 1980).

Entretanto, plântulas de bromélias são raramente encontradas em restinga, principalmente nas áreas entre moitas (Freitas et al. 2000; Mantovani \& Iglesias 2002). Harper (1967) afirma que a fase de plântula é a mais sensível frente às adversidades ambientais, dentre todas que constituem o ciclo de vida de uma planta. Tal fato é especialmente determinado em vegetações sobre substrato arenoso, onde o estabelecimento de plântulas é muito limitado pelas condições abióticas (Maun 1994). De fato, nas áreas entre moitas da restinga aberta de Maricá a temperatura do solo e do ar podem ultrapassar respectivamente $60^{\circ} \mathrm{Ce}$ $30^{\circ} \mathrm{C}$; a intensidade luminosa supera os 1.600 $\mu$ moles $\mathrm{m}^{-2} \mathrm{~s}^{-1}$, enquanto a água do solo na superfície chega a $0,9 \mathrm{~g}_{\mathrm{H}_{\mathrm{O}} \mathrm{O}} / \mathrm{g}_{\text {solo }}$ contra mais de $40 \mathrm{~g}_{\mathrm{H}_{2}} / \mathrm{g}_{\text {solo }}$ dentro das moitas (Mantovani 2002, Mântovani \& Iglesias 2002).

Portanto, caso bromélias possam realmente agir como plantas pioneiras (Hay \& Lacerda 1980), elas deveriam apresentar capacidade de estabelecimento de plântulas em áreas entre moitas. Considerando que no solo oligotrófico da restinga tal capacidade seria em muito facilitada pela presença de tricomas de absorção, a referida ausência de plântulas poderia estar ligada ao tempo de diferenciação destas estruturas.

Este trabalho analisa, em bases morfológicas, as primeiras fases de vida compreendendo desde a germinação das sementes até a fase inicial de plântula, de três espécies de bromélias terrestres com potencial para exercer papel facilitador em restinga (Mantovani \& Iglesias 2002): Aechmea nudicaulis; Neoregelia cruenta (Bromelioideae) L. B. Smith e Vriesea neoglutinosa Mez(Tillandsioideae). Tal análise será efetuada através de microscopia ótica e eletrônica de varredura (MEV). Visto que nas restingas tais bromélias apresentam também reprodução assexuada, esta análise foi estendida aos respectivos rametes. $\mathrm{O}$ objetivo é gerar subsídios para entender o estabelecimento destas espécies na restinga de Barra de Maricá.

\section{Materiais e Métodos}

Para análise de propágulos oriundos da germinação de sementes, procedeu-se primeiramente na coleta de frutos no campo. Frutos intactos, sem sinal de predação, foram coletados no campo e trazidos para laboratório, onde foram triados e tiveram suas sementes 
retiradas. As sementes de $N$. cruenta e A. nudicaulis possuem envoltório mucilaginoso, mas testes iniciais demonstraram que o mesmo não impedia a germinação. Com relação a $V$. neoglutinosa, somente o coma (conjunto de pêlos da semente para dispersão anemocórica (Benzing 1978)) foi parcialmente retirado para inibir o aparecimento de fungos. Sementes não predadas foram separadas e colocadas para germinar em placas de petri (diâmetro $3,5 \mathrm{~cm}$ ) cobertas com papel de filtro constantemente umedecido, dispostas sob temperatura do ar de $27^{\circ} \mathrm{C}$ e irradiância de $3,5 \mu$ moles $\mathrm{m}^{-2} \mathrm{~s}^{-1}$ geradas por lâmpadas fluorescentes. A temperatura do ar foi determinada com termômetro digital Fluke 52, com $0,1^{\circ} \mathrm{C}$ de precisão, equipado com um termopar de cobreconstantan e a irradiância através do quantum sensor Li-190SB acoplado a um quantumradiômetro Li-Cor 189SB (Mantovani 2001). Para cada espécie, três placas contendo 10 sementes foram preparadas.

$\mathrm{O}$ acompanhamento das primeiras fases de vida pós-germinação foi feito até 18 dias, sendo o dia em que houve emissão da radícula considerado como primeiro dia. A descrição morfológica das plântulas seguiu a metodologia proposta por Pereira (1988) para germinação e desenvolvimento pós-germinativo de espécies de bromélias de Bromelioideae. Foram coletadas sementes germinadas em diferentes dias de tratamento, mas que sempre apresentaram etapas pré-escolhidas. Tais etapas foram "emissão da radícula", "emissão da plúmula" e "completa expansão da plúmula com emissão da segunda folha".

Para os rametes, oriundos de reprodução assexuada, foram coletados no campo indivíduos que apresentassem apenas um ramete ainda em estágio inicial de formação. Trazidos para o laboratório, cada ramete foi separado da planta-mãe e cuidadosamente desfolhado. Para fins de comparação com os propágulos oriundos de sementes, que tinham pouco tempo de formação, foi separado o meristema apical do caule de cada ramete.

Os materiais escolhidos foram analisados através de Microscopia Eletrônica de
Varredura. Primeiramente, os materiais foram fixados em álcool $70^{\circ}$ GLe depois desidratados em série alcoólica crescente. Posterior ao processo de desidratação, procederam-se os de preparo através do ponto-crítico e metalização com liga de ouro-paládio (Mantovani \& Vieira 2000). Os materiais foram colocados em suportes adequados e vistos em microscópio JEOL JSM-5310, com aceleração de $20 \mathrm{kV}$. Observações complementares foram efetuadas através de estereomicroscopia e microscopia ótica.

\section{Resultados}

A germinação das sementes de $A$. nudicaulis iniciou-se após o terceiro dia de hidratação, fato evidenciado através da emissão da radícula (figura 1a). A radícula de A. nudicaulis tem formato cônico e tão logo é emitida, apresenta densa vilosidade composta por pêlos radiculares. Após oito dias de iniciada a germinação, é visível a abertura da fenda cotiledonar no ápice do eixo hipocótilo, determinando o aparecimento da bainha cotiledonar, que passa a envolver a plúmula, ou primeira folha em estágio inicial de formação (figura 1b). Nesta fase já é também visível o colo, de onde partem pêlos radiculares em profusão.

No $11^{\circ}$ dia após a germinação, a plúmula terminou sua expansão, constituindo-se então na primeira folha formada (figura 1c). Sustentando-a aparece o epicótilo, circundado pela bainha cotiledonar. Junto à porção proximal do epicótilo, aparece a segunda folha em formação (figura 1d). É possível detectar a presença de tricomas unisseriados pluricelulares em pequena escala no bordo da primeira folha (figura 1c) e na segunda folha em começo de formação (1d). Observações ao nível da microscopia ótica demonstram que tais tricomas são formados por série de duas a quatro células. Entretanto não constituem escamas peltadas pluricelulares, comuns na família Bromeliaceae. Estômatos são visíveis a partir da segunda folha (figura 1f).

A espécie $N$. cruenta apresentou padrão geral de desenvolvimento da plântula 
semelhante ao encontrado em $A$. nudicaulis. Na figura 2a está mostrada semente de $N$. cruenta em estágio inicial de emissão da radícula, no primeiro dia de germinação. É possível determinar em corte longitudinal a posição do suspensor ("haustro" segundo Pereira 1988), ligando o endosperma à região
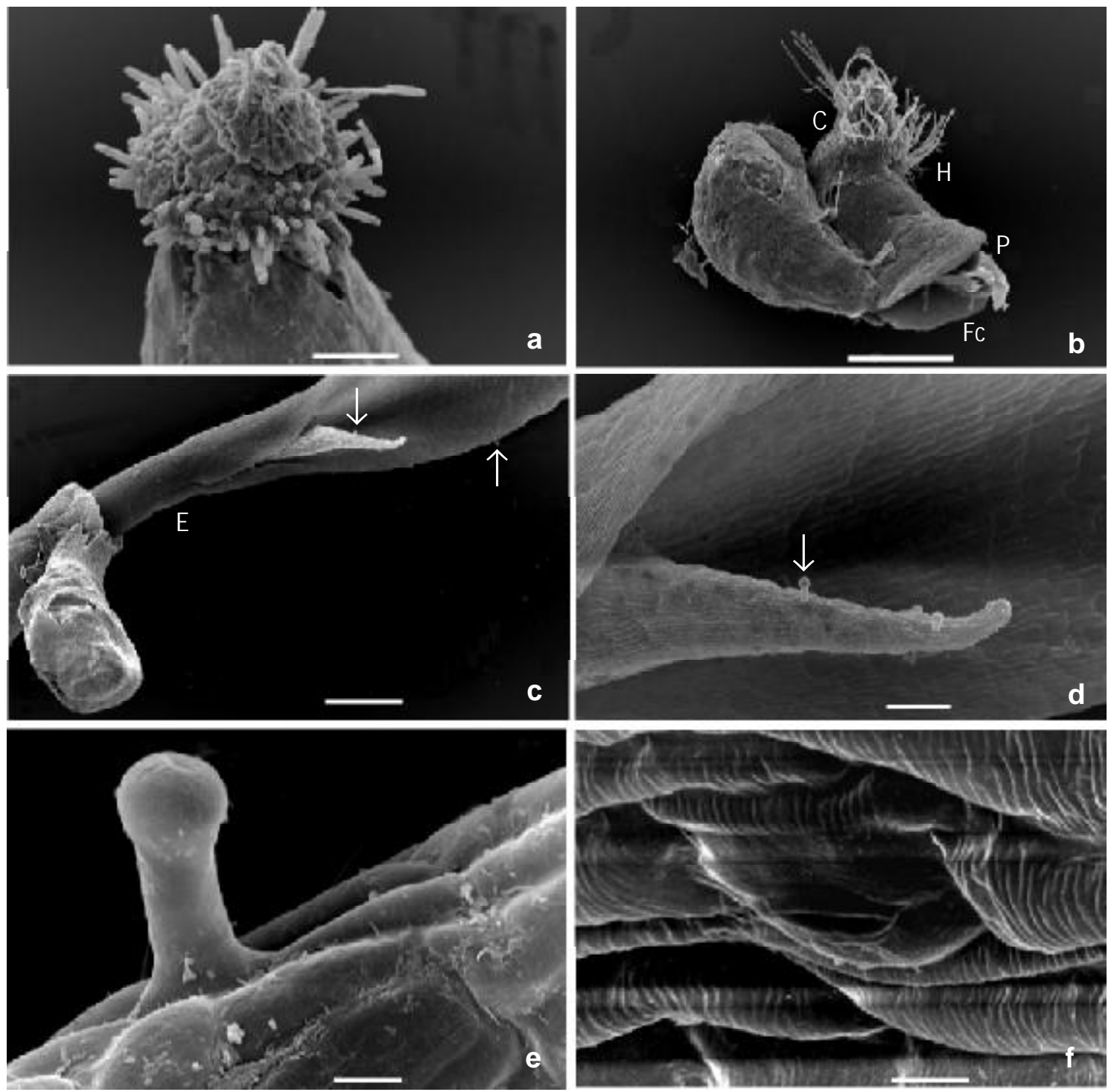

Figura 1 - Microscopia eletrônica de varredura das primeiras fases de vida de Aechmea nudicaulis. a - Primeiro dia de germinação. Note emissão de radícula e densa vilosidade (barra=100 $\mu \mathrm{m}$ ); b - Plântula após oito dias de iniciada a germinação. Note a abertura da fenda cotiledonar $(\mathrm{Fc})$ e a saída da plúmula $(\mathrm{P})$. Sustentando a plúmula, o eixo hipocótilo $(\mathrm{H})$ liga a bainha cotiledonar ao colo $(\mathrm{C})$, de onde partem pêlos radiculares em profusão (barra $=500 \mu \mathrm{m}$ ); c - Plântula com 11 dias após a germinação. Note a plúmula totalmente expandida e a segunda folha ainda em desenvolvimento e a presença do eixo epicótilo (E). Tricomas foliares são visíveis na primeira e segunda folhas (setas) (barra $=500 \mu \mathrm{m}$ ); $\mathrm{d}$ - Detalhe em maior aumento da figura $\mathrm{C}$, mostrando tricomas (seta) presentes na segunda folha. Uma observação detalhada permite ver que tais tricomas estão presentes também no bordo da plúmula, mostrado na figura $\mathrm{C}$ (barra $=100 \mu \mathrm{m}$ ); $\mathrm{e}$ - Detalhe do tricoma presente nas folhas de plântulas de $A$. nudicaulis (barra $=10 \mu \mathrm{m}$ ); - Detalhe do estômato ocorrente na segunda folha (barra=5 $\mu \mathrm{m}$ ). 
o hipocótilo já desenvolvido apresenta abertura da fenda cotiledonar e a extrusão da plúmula (figura 2b). É possível perceber uma bainha cotiledonar envolvendo quase completamente a primeira folha em formação, além de denso sistema de pêlos radiculares. Na figura 2c, as
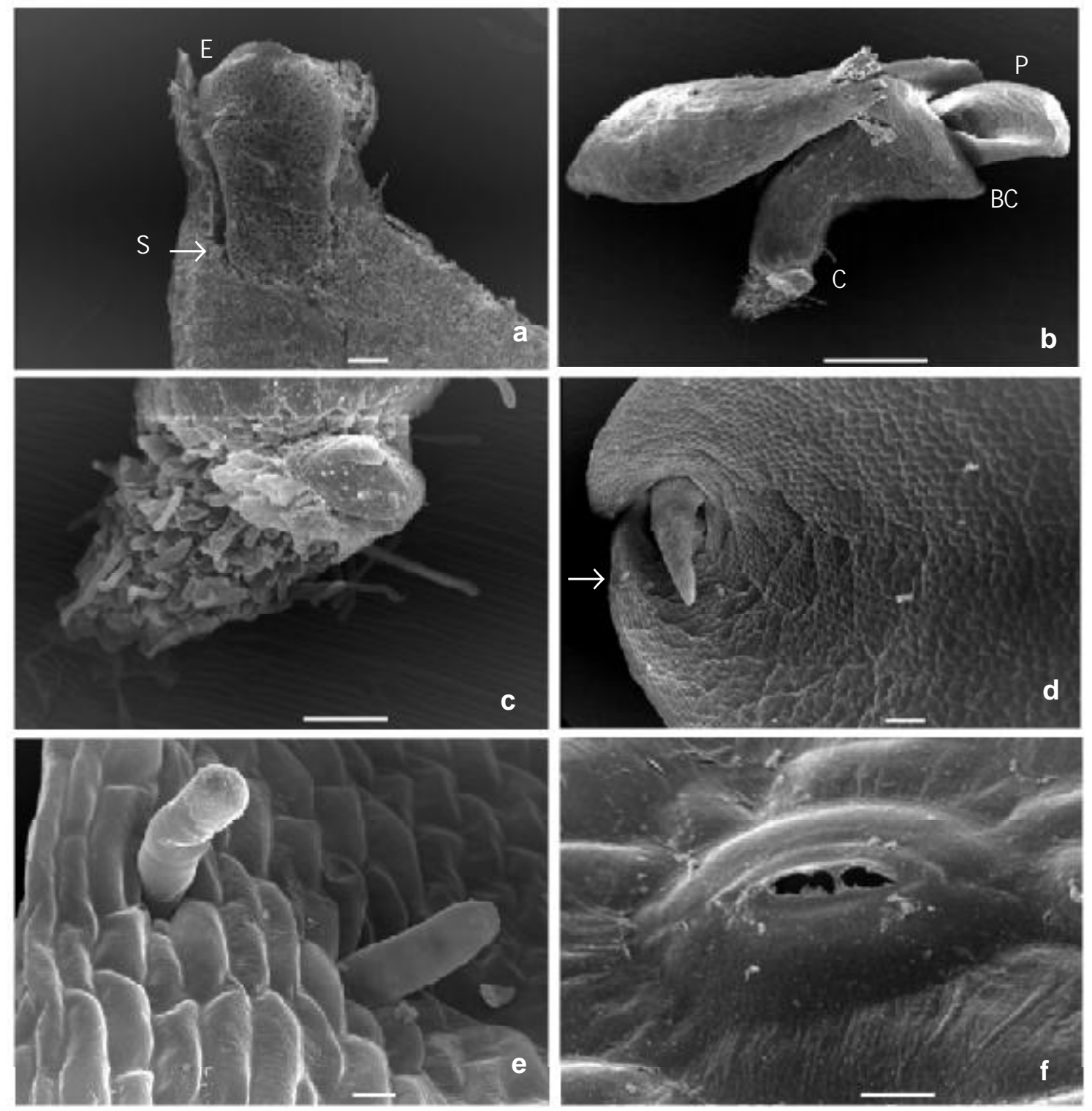

Figura 2 - Microscopia eletrônica de varredura das primeiras fases de vida de Neoregelia cruenta. a - Corte longitudinal da semente mostrando primeiro dia de germinação. Note emissão de radícula e a presença do suspensor (S) ligando as reservas da semente ao embrião $(\mathrm{E})(\mathrm{b} a r r a=100 \mu \mathrm{m})$; b - Plântula após 11 dias de iniciada a germinação. Note a abertura da fenda cotiledonar e a bainha cotiledonar $(\mathrm{BC})$ que envolve a plúmula $(\mathrm{P})$ em formação. Sustentando a plúmula, o eixo hipocótilo, liga a bainha cotiledonar ao colo (C) de onde partem pêlos radiculares em profusão (barra=500 $\mu \mathrm{m}$ ); $\mathrm{c}$ - Detalhe do ápice da radícula mostrando a região do colo, de onde partem pêlos radiculares (barra=100 $\mu \mathrm{m}$ ); $\mathrm{d}$ - Plântula com 15 dias após a germinação. Note a plúmula totalmente expandida e a segunda folha ainda em desenvolvimento. Note presença de tricomas na plúmula e segunda folha (seta) $($ barra $=500 \mu \mathrm{m})$; e - Detalhe em maior aumento da figura d, mostrando tricomas unisseriados na plúmula (barra $=10 \mu \mathrm{m}) ; \mathrm{f}$ - Detalhe do estômato ocorrente na segunda folha (barra $=5 \mu \mathrm{m})$.

Rodriguésia 56 (87): 73-84. 2005 
presença de tricomas na primeira e segunda folhas, constituídos por duas a três células dispostas de forma unisseriada (figuras $2 \mathrm{~d}$ e 2e). Estômatos estão presentes na segunda folha, ainda involuta e em formação (figura $2 f$ ).
A germinação e o desenvolvimento de $V$. neoglutinosa apresentaram algumas diferenças em comparação às outras duas espécies. A semente de $V$. neoglutinosa recém germinada, com um dia de emissão da
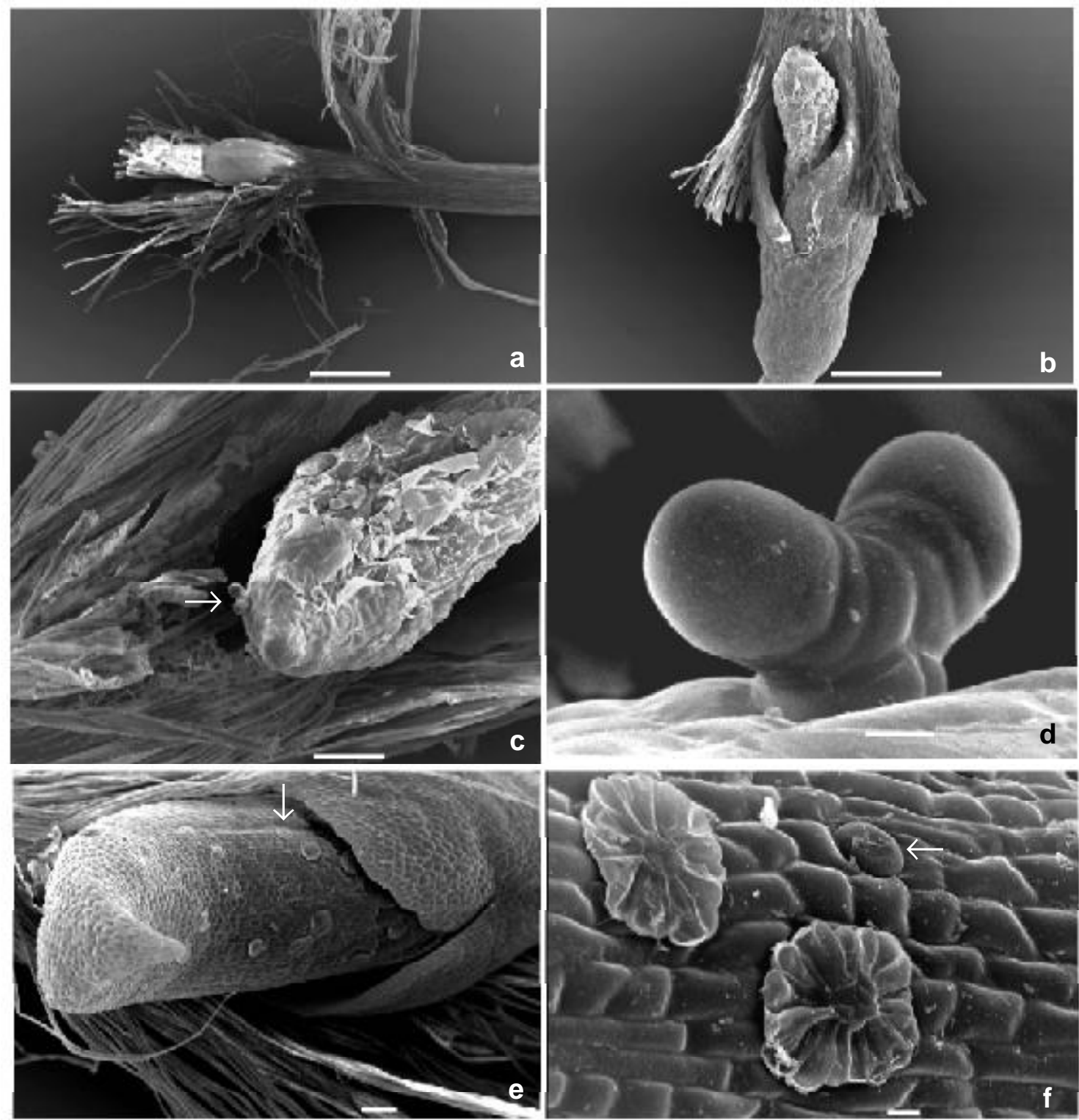

Figura 3 - Microscopia eletrônica de varredura das primeiras fases de vida de Vriesea neoglutinosa. a - Primeiro dia de germinação. Note emissão da radícula. As estruturas na porção dis tal do embrião não são pêlos radiculares, mas o ápice da semente que se destaca e acompanha por vezes o alongamento da radícula (barra $=500 \mu \mathrm{m}$ ); $\mathrm{b}$ - Plântula após 15 dias de iniciad a a germinação. Note a abertura da fenda cotiledonar e a extrusão da plúmula. Barra $=500 \mu \mathrm{m} ; \mathrm{c}-$ Detalhe da plúmula da figura $\mathrm{b}$. Note a presença de tricomas (seta) $(\mathrm{b} a r \mathrm{ar}=100 \mu \mathrm{m}) ; \mathrm{d}$ - Detalhe do tricoma indicado na figura $\mathrm{c}$. Note a estrutura em halteres, e a presença de diversas divisões celulares simétricas (barra $=10 \mu \mathrm{m}$ ); e - Plântula de $V$. neoglutinosa com 18 dias de iniciada a germinação. Note a presença de várias escamas (seta) (barra=100 $\mu \mathrm{m}$ ); $\mathrm{f}$ - Detalhe das escamas presentes na primeira folha de $V$. neoglutinosa. Note duas séries concêntricas de células: a primeira representada pelas quatro células do disco central, e a segunda representada pelas células que constituem o escudo. Note estômato posicionado próximo às escamas (seta) (barra=10 $\mu \mathrm{m})$. 
radícula, apresenta ausência de pêlos radiculares (figura $3 a$ ), que não ocorreram até o fim do estudo (18 dias). Nota-se que o desenvolvimento da espécie em questão foi mais lento do que o de A. nudicaulis e $N$. cruenta. Tal afirmação pode ser demonstrada pelo fato de que a saída da plúmula através da fenda cotiledonar (figura 3b), só se deu 15 dias após a emissão da radícula. Na plúmula em desenvolvimento é possível detectar tricomas na epiderme em diferentes estágios de formação (figura 3c). Um destes tricomas está mostrado em detalhe na figura 3d. Embora tenha aparência de um tricoma pluricelular ramificado, trata-se de uma escama de bromélia em início de formação. Tal estrutura em halteres é característica anatômica que precede a série de divisões celulares que darão origem a escama. Após 18 dias de formação, a plúmula de $V$. neoglutinosa apresenta-se bem mais expandida e comparativamente mais espessa do que as presentes em $A$. nudicaulis e $N$. cruenta. Nota-se nesta fase a ocorrência de escamas (figura 3e). É possível determinar o disco central formado por apenas quatro células, circundado pelas células do escudo (figura 3f). Note na mesma figura a presença de um estômato na primeira folha.

Na figura 4 estão mostrados os ápices meristemáticos das três espécies em estudo. Todas elas apresentaram escamas ainda nas folhas em formação, ao contrário do encontrado para os propágulos oriundos de sementes. A figura 4a mostra o ápice de $V$. neoglutinosa, com diversas escamas distribuídas pela superfície. Uma escama dessa espécie é mostrada em detalhe na figura $4 \mathrm{~b}$. Note como a mesma está completamente formada, apresentando três séries de células, sendo 4 no disco central, 8 no anel em volta do disco central, e as restantes pertencentes ao escudo. O meristema das espécies $N$. cruenta e A. nudicaulis são mostrados na figura $4 \mathrm{c} e$ $4 \mathrm{e}$, respectivamente, enquanto escamas das duas espécies são mostradas em detalhe nas figuras $4 \mathrm{~d}$ e $4 \mathrm{f}$. Note como que, ao contrário de $V$. neoglutinosa, as escamas de $N$. cruenta e A. nudicaulis são constituídas por células dispostas de maneira assimétrica, onde não se detecta facilmente um disco central.

\section{Discussão}

A viabilidade de sementes e o padrão da germinação estão entre os aspectos menos estudados em reprodução de bromélias (Pereira 1988; Benzing 2000). Entretanto, os poucos trabalhos existentes sobre germinação e estabelecimento de bromélias, realizados em copa de árvores, indicam alta taxa de mortalidade na fase de plântula (Benzing 1978; Mondragón et al. 1999). Benzing (1990) afirma que tal fato está ligado principalmente à aridez, que torna as plântulas suscetíveis à dessecação, pois em geral as mesmas têm pequeno tamanho e baixa razão superfície/volume. Entretanto, Benzing (2000) cita que tal mortalidade não ocorre no mesmo padrão para as plântulas de todas as espécies de bromélias, pois aquelas pertencentes à subfamília Tillandsioideae são, em geral, mais resistentes às condições adversas das copas. Entre os caracteres que garantem tal resistência para a subfamília Tillandsioideae está a presença de tricomas foliares absorventes, denominados usualmente por escamas (Benzing 1976).

Os dados aqui apresentados demonstram que as plântulas de $N$. cruenta e A. nudicaulis não apresentam escamas nas folhas pelo menos até 11 dias depois de emissão da radícula. Desta forma, findas as reservas da semente, as mesmas dependeriam exclusivamente do sistema radicular para crescimento e nutrição. De fato, Benzing (2000) cita que para plântulas de indivíduos de Bromelioideae, as raízes são a única via de absorção de água e nutrientes. Por isso o autor afirma que tais plântulas raramente se estabelecem em substratos secos, mas apenas em substratos onde haja umidade. Mantovani \& Iglesias (2002) mostram que os solos nas áreas entre moitas na restinga de Barra de Maricá são pobres em nutrientes e apresentam baixa disponibilidade de água nos primeiros centímetros do solo. Nestas condições em que o solo possui poucos nutrientes e água, a presença de escamas seria de alto valor adaptativo para o estabelecimento, pois 

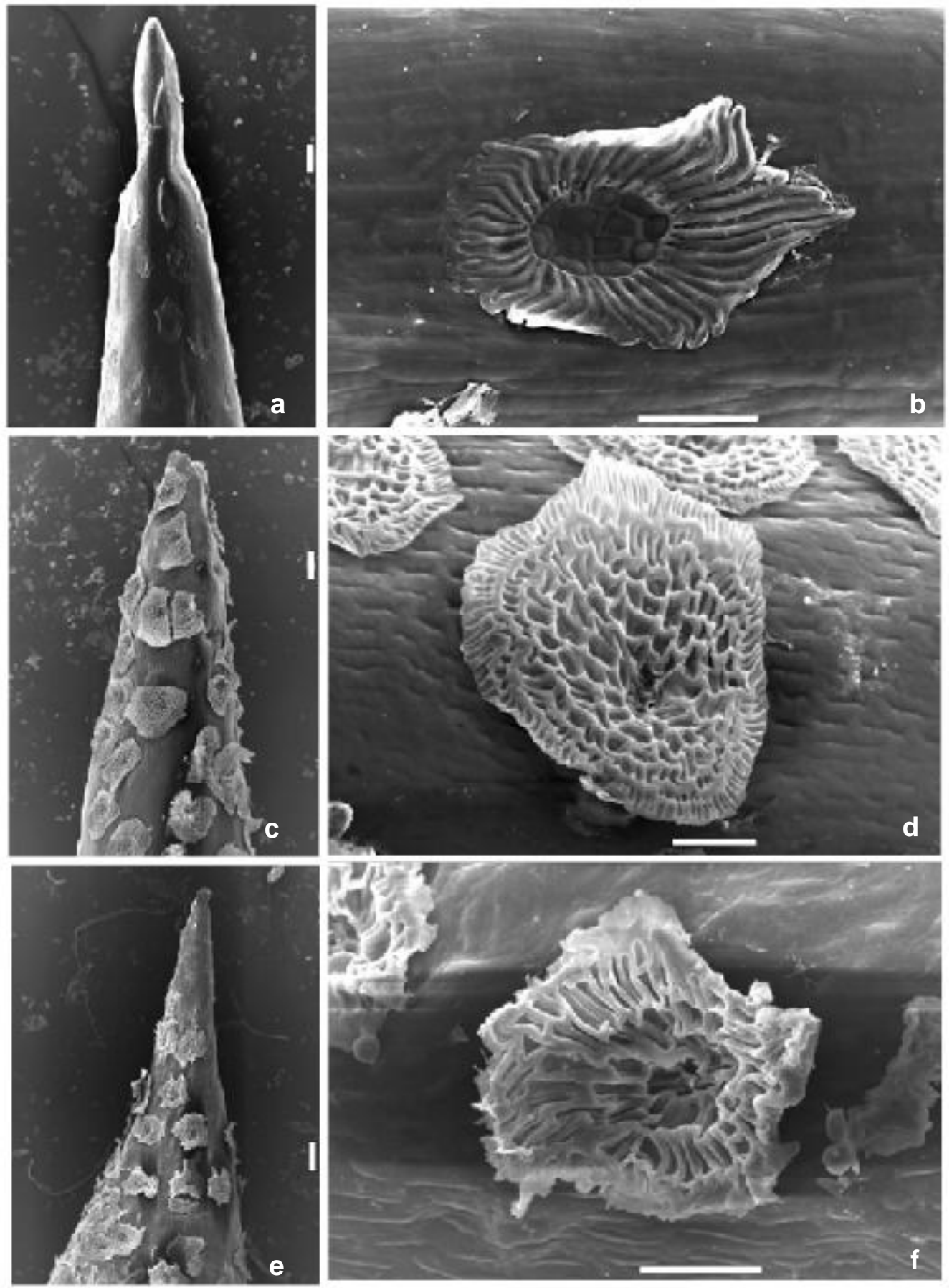

Figura 4 - Microscopia eletrônica de varredura das primeiras folhas junto ao meristema apical do caule (MAC) de brotos oriundos da reprodução assexuada de bromélias terrestres de restinga. a - MAC do broto de Vriesea neoglutinosa. Uma observação em detalhe permite ver escamas fortemente adpressas à superfície do primórdio foliar (barra=100 $\mu \mathrm{m}$ ); $\mathrm{b}$ - Detalhe da escama presente nas folhas junto ao MAC de V. neoglutinosa. Note escama organizada em três séries concêntricas de células: a primeira representada pelas 4 células do disco central; a segunda pelas 8 células que envolvem o disco central; e a terceira representada pelas demais células do escudo. Note a forte simetria da estrutura (barra $=50 \mu \mathrm{m}$ ); $\mathrm{c}$ - MAC do broto de $N$. cruenta. Note escamas distribuídas pela superfície foliar $(\mathrm{b} a r r a=100 \mu \mathrm{m}) ; \mathrm{d}$ - Detalhe da escama presente nas folhas junto ao MAC de $N$. cruenta. Note falta de simetria na distribuição das células do escudo (barra=50 $\mu \mathrm{m}$ ); e - MAC do broto de $A$. nudicaulis. Note escamas distribuídas pela superfície foliar $(\mathrm{b} a r r a=100 \mu \mathrm{m}) ; \mathrm{f}$ - Detalhe da escama presente nas folhas junto ao MAC de A. nudicaulis. Note falta de simetria na distribuição das células do escudo (barra=50 $\mu \mathrm{m}$ ). 
possibilitaria absorção de água e nutrientes por via foliar (Benzing 1976; Lüttge et al. 1986). Hay \& Lacerda (1984) afirmam que para as restingas, uma das principais vias de entrada de recursos é a via aérea, através da salsugem. Portanto a ausência de escamas limitaria a capacidade de estabelecimento de A. nudicaulis e $N$. cruenta em áreas entre moitas, contrariando a hipótese de Hay \& Lacerda (1980), de que as bromélias conseguiriam iniciar moitas em áreas sem vegetação.

As primeiras folhas produzidas por $V$. neoglutinosa apresentaram razão superfície/ volume superior a das folhas de A. nudicaulis e $N$. cruenta, garantindo maior suculência foliar (Mantovani 1999a; b). Benzing (1990) afirma que a maior suculência foliar é comum para plântulas da subfamília Tillandsioideae que apresentam tanques quando adultas (ex.: gêneros Vriesea e Alcantarea). Benzing (1990) relata que tais plântulas têm morfologia semelhante a espécies atmosféricas do gênero Tillandsia, caracterizando portanto dois tipos foliares ao longo do ciclo vital. Tal fenômeno é tido como heterofilia e tem caráter adaptativo, visto que as "plântulas tillandsioides" aparentemente podem resistir mais à dessecação que as formas tanque adultas (Adams \& Martin 1986; Reinert \& Meirelles 1993).

A espécie $V$. neoglutinosa produz escamas ainda na primeira folha formada, porém somente após 15 dias depois de emitida a radícula. Benzing $(1978,1990,2000)$ cita que o menor tempo conhecido para o surgimento de escamas, em espécies de Tillandsioideae, seria de três meses após a germinação para Tillandsia circinnata Schlecht. Portanto, este tempo, denominado "indice de preparação" pelo referido autor, pode ser bem menor. Porém não foi ainda comprovado para nenhuma destas duas espécies se essas escamas possuem capacidade de absorção. A figura $3 \mathrm{f}$ mostra células do disco central túrgidas, enquanto que a figura 4b mostra células aparentemente sem turgência. Benzing (1976) mostra que as células do disco e escudo de escamas são mortas e vazias quando completamente formadas. O autor explica que as células mortas agem por capilaridade, armazenando no lume da célula a água que entra em contato com a superfície da folha. Considerando que após 18 dias, as escamas presentes nas plântulas das espécies aqui estudadas apresentavam somente duas séries de células (figura 3f), enquanto no ramete haviam três séries (figura 4b), é possível que outras divisões celulares ainda precisassem ser realizadas até o pleno desenvolvimento anatômico da estrutura. Sendo assim, células vivas ainda estariam presentes, o que impediria as escamas de exercer com eficiência sua função de absorção por capilaridade. Sthrel (1983) fornece indícios que auxiliam a análise dessa hipótese. A autora cita que espécies de Vriesea apresentam o escudo da escama formado por três a quatro séries de células, a contar das quatro células do disco central. Assim, Vriesea modesta Mez tem número de células do escudo na série 4; 8, 32; Vriesea platynema Gaudich. 4, 8, 64 e Vriesea platzmannii E. Morr. 4, 8, 16, 64. Entretanto a morfologia das escamas pode mudar mesmo ao longo da superfície de uma mesma folha (Benzing 1990), de forma que mais estudos são necessários para comprovar a hipótese sobre a funcionalidade das escamas das plântulas de $V$. neoglutinosa.

Entretanto, independente da funcionalidade das escamas, os dados aqui demonstram que $V$. neoglutinosa tem desenvolvimento mais lento e não apresenta raízes adventícias ou pêlos radiculares na fase inicial da germinação. Benzing (2000) afirma que nos membros de Tillandsioideae, como espécies de Vriesea, as raízes das plântulas oriundas de sementes só aparecem de várias semanas a meses após a saída da primeira folha. Sendo assim, a plântula de $V$. neoglutinosa é intensamente dependente das folhas para a sobrevivência. A ausência de escamas até pelo menos 11 dias depois de iniciada a germinação, combinada com a ausência de raízes, colocaria $V$. neoglutinosa na mesma condição das outras duas espécies em estudo.

Em comparação com plântulas de Bromelioideae, as plântulas de Tillandsioideae teriam maior capacidade de se estabelecer em 
substratos mais secos e iluminados devido justamente às características foliares de superfície/volume e presença de escamas (Benzing 1990). Tal fato certamente não ocorre na restinga, pois embora ocorram freqüentemente em Barra de Maricá pelo menos duas espécies de Tillandsia epífitas (Tillandsia stricta Soland. e Tillandsia usneoides (L.) L.), plântulas oriundas de sementes de nenhuma das duas é vista no chão (A. Mantovani, observação pessoal). Reinert (1995) cita que adultos de T. stricta são vistos como terrestres, mas que provavelmente caíram ao chão por quebra de galhos. Um indício de que o substrato é fator altamente limitante do estabelecimento de bromélias por via sexuada na restinga é o fato das espécies aqui estudadas ocorrerem também como epífitas na restinga de moitas e florestas adjacentes (Lacerda \& Hay 1982; Wendt 1997; Fontoura 2001), onde provavelmente só poderiam chegar através de sementes.

Freitas et al. (1998) e Silva \& Oliveira (1989) mostram que embora sejam encontradas nas áreas entre moitas, a principal zona de distribuição das bromélias em ecossistemas de restinga de Barra de Maricá é junto as moitas. Benzing (2000) cita que o comportamento dos dispersores, a exposição luminosa e umidade do substrato influenciam na distribuição das bromélias. Segundo Zotz (1997), a distribuição de bromélias adultas segue a distribuição de locais onde potencialmente existem mais chances de germinação e estabelecimento das plântulas. Tais condições existem apenas dentro das moitas (Mantovani \& Iglesias 2002), ou no máximo, em regiões de borda das moitas com maior disponibilidade de água para as sementes.

Freitas et al. (1998) analisaram fenômeno semelhante de ausência de plântulas para populações de Nidularium procerum Lindm. e Nidularium innocentii Lem. crescendo em florestas inundadas no Rio de Janeiro. Os autores enfatizam a necessidade de determinar se a não concretização da reprodução sexuada ocorre no início do processo de regeneração (da polinização à maturação das sementes) ou tardiamente (da dispersão atéo estabelecimento). Com relação às espécies $A$. nudicaulis, $N$. cruenta e V. neoglutinosa, os dados disponíveis demonstram que as sementes são viáveis, e que a falência do processo regenerativo se deve provavelmente à morte das plântulas, devido às condições adversas ao estabelecimento numa escala tanto espacial quanto temporal na restinga de Barra de Maricá (Mantovani 2002). Para explicar a razão da ausência de plântulas, Freitas et al. (1998) propõem a seguinte hipótese: a falta de plântulas ocorreria devido a um possível "choque de gerações", isto é, o ambiente é benéfico para a planta-mãe, mas não para as sementes. Neste caso, a forma principal de reprodução para as bromélias de restinga seria a reprodução assexuada.

Elevadas quantidades de biomassa, nitrogênio e fósforo são alocadas na produção de rametes (reprodução assexuada) de $A$. nudicaulis e $N$. cruenta, se comparadas à quantidade alocada nas inflorescências (reprodução sexuada) (Mantovani 2002). A presença de escamas mesmo nas folhas mais novas dos rametes determina que, através da reprodução as sexuada, estas espécies conseguem superar o longo período necessário para a produção de uma planta auto suficiente oriunda de sementes. Benzing (2000) relata que o sucesso do estabelecimento de bromélias seria dependente da capacidade das plântulas em chegarem até determinado tamanho que viabilizasse a sobrevivência. Enquanto que as plântulas são altamente suscetíveis à mortalidade (Mantovani 2002), os rametes já surgiriam em tamanho superior, garantindo mais rapidez, menor risco e maior eficiência de estabelecimento (Harper 1967). Tal fato é provavelmente o determinador do sucesso das bromélias no estabelecimento em condições de restinga: elevada alocação de recursos em estruturas propagadoras com alta capacidade de estabelecimento (Mantovani 2002).

\section{Agradecimentos}

Os autores agradecem à Sra. Noêmia Alves (Laboratório Hertha Mayer/UFRJ) pelo auxílio no uso do microscópio eletrônico de varredura, e aos revisores pelas valiosas sugestões. 


\section{REFERÊnCIaS Bibliográficas}

Adams, W. W. \& Martin, C. E. 1986. Heterophylly and its relevance to evolution within the Tillandsioideae. American Journal of Botany 9: 121-125.

Benzing, D. H. 1976. Bromeliad trichomes: structure, function and ecological significance. Selbyana 1: 330-348

Benzing, D. H. 1978. Germination and early establishment of Tillandsia circinnata Schlecht. (Bromeliaceae) on some of its hosts and other supports in south Florida. Selbyana 5: 95-106.

Benzing, D. H. 1990. Vascular epiphytes: General Biology and related biota. New York, Cambridge University Press, 353p.

Benzing, D. H. 2000. Bromeliaceae: profile of an adaptive radiation. Cambridge University Press, Cambridge, UK. 690p.

Fontoura, T. 2001. Bromeliaceae and other epiphytes: stratification and other resources available to animals at the Jacarepiá State Ecological Reserve in Rio de Janeiro. Bromelia 6 (1/4): 33-39.

Freitas, C.A.;Scarano, F.R. \& Wendt, T. 1998. Habitat choice in two facultative epiphytes of the genus Nidularium (Bromeliaceae). Selbyana 19(2): 236-239.

Freitas, A. F. N.; Cogliatti-Carvalho, L., Sluys, M \& Rocha, C. F. D. 2000. Distribuição espacial de bromélias na restinga de Jurubatiba, Macaé, RJ. Acta Botanica. Brasílica 14(1): 175-180.

Harper, J. L. 1967. A darwinian approach to plant ecology. Journal of Ecology 55(2): 247-270.

Hay, J. D. \& Lacerda, L. D. (1980). Alterações nas características do solo após fixação de Neoregelia cruenta (R. Grah.) L. B. Smith (Bromeliaceae) em um ecossistema de restinga. Ciência \& Cultura 32 (7): 863867.

Hay, J. D. \& Lacerda, L. D. 1984. Ciclagem de nutrientes no ecossistema de restinga. In: Lacerda, L. D.; Araujo, D. S. D.; Cerqueira, R. \& Turcq, B. (eds.) Restingas; origens, estruturas e processos. CEUFF,
Rio de Janeiro, p: 457-473.

Hay, J. D.; Lacerda, L. D. \& Tan, A. L. 1981. Soil cation increase in a tropical sand dune ecosystem due to a terrestrial bromeliad. Ecology 62 (5): 1392-1395.

Henriques, R. P. B. \& Hay, J.D. 1992. Nutrient content and the structure of a plant community of a tropical beach dune system in Brazil. Acta Ecologica 13: 101117.

Lacerda, L. D. \& Hay, J. D. 1982. Habitat of Neoregelia cruenta (Bromeliaceae) in coastal sand dune of Maricá, Brazil. Revista de Biologia Tropical 30:171-173.

Lüttge, U., E., Klanke, B., Griffiths, H., Smith, J. A. C. \& Stimmel, K. H. 1986. Comparative ecophysiology of CAM and C3 bromeliads. V. Gas exchange and leaf structure of the C3 bromeliad Pitcairnia integrifolia. Plant, Cell and Environment 9: 411-419.

Mantovani, A. 1999a. A method to improve leaf succulence quantification. Brazilian Archives of Biology and Technology 42 (1): 9-14.

Mantovani, A. 1999b. Leaf morphophysiology and distribution of epiphytic aroids along a vertical gradient in a Brazilian Rain Forest. 1999. Selbyana 20(2): 241-249

Mantovani, A. 2001. Leaf orientation in hemiepiphytic and holo-epiphytic aroids: significance to the leaf water and temperature balance. Leandra 15: 91-103.

Mantovani, A. 2002. Bromélias terrestres na restinga de Barra de Maricá: alocação de recursos na floração, germinação de sementes, estabelecimento e papel facilitador. Tese de Doutorado, Universidade Federal do Rio de Janeiro, Programa de Pós-Graduação em Ecologia, 164p.

Mantovani, A. \& Vieira, R. C. 2000. Leaf micromorphology of Antarctic pearlwort Colobanthus quitensis (Kunth) Bartl. Polar Biology 23: 531-538.

Mantovani, A. \& Iglesias, R. R. 2002. Bromélias terrestres na restinga de Barra de Maricá, RJ: influência sobre o microclima, 
o solo e a estocagem de nutrientes em ambientes de borda de moitas. Leandra 16: 17-36.

Mattos, E.A.; Grams, T.E.E.; Ball, E.; Franco, A. C.; Haag-Kewer, A.; Herzog, B.; Scarano, F. \& Lüttge, U. 1997. Diurnal patterns of chlorophyll a fluorescence and stomatal conductance in species of two types of coastal tree vegetation in southeastern Brazil. Trees 11: 363-369.

Maun, M. A. 1994. Adaptations enhancing survival and establishment of seedlings on coastal dune systems. Vegetation 111: 59-70.

Mondragón, D.; Durán, R. ; Ramírez, I. \& Olmsted, I. 1999. Population dynamics of Tillandsia brachycaulus Schtdl. (Bromeliaceae) in Dzibilchaltun National Park, Yucatán. Selbyana 20(2): 250-255.

Pereira, T. S. 1988. Bromelioideae (Bromeliaceae): Morfologia do desenvolvimento pós-seminal de algumas espécies. Arquivos do Jardim Botânico do Rio de Janeiro. 29: 115-154.

Reinert, F. 1995. On the Bromeliaceae of the restinga of Barra do Maricá in Brazil: environmental influence on the expression of crassulacean acid metabolism. Tese de Doutorado, Department of Agricultural and Environmental Science, University of New Castle, Newcastle, Inglaterra. 239p.
Reinert, F. \& Meirelles, S. T. 1993. Water acquisition strategies shifts in the heterophyllous saxicolous bromeliads Vriesia geniculata (Wawra) Wawra. Selbyana 14: 80-88.

Reinert, F.; Roberts, A.; Wilson, J. M.; Ribas, L.; Cardinot, G. \& Griffiths, H. 1997. Gradation in nutrient composition and photosynthetic pathways across the Restinga vegetation of Brazil. Botanica Acta 110: 135-142.

Silva, J. G. \& Oliveira, A. S. 1989. A vegetação de restinga no Município de Maricá, RJ. Acta Botanica Brasilica 3(2): 253-272.

Strehl, T. 1983. Forma, distribuição e flexibilidade dos tricomas foliares usados na filogenia de bromeliáceas. Iheringia 31 : 105-119.

Tomlinson, P. B. 1969. CommelinalesZingiberales. In: Anatomy of the monocotyledons. ed. C. R. Metcalfe. Oxford: Clarendon Press. pp. 193-294.

Wendt, T. 1997. A review of the subgenus Pothuava (Baker) Baker and Aechmea Ruiz \& Pav. (Bromeliaceae) in Brazil. Botanical Journal of Linnean Society 125 : 245-271.

Zotz, G. 1997. Substrate use of 3 epiphytic bromeliads. Ecography 20(3): 264-270. 
